\title{
Management of Intertrochanteric Fractures of Femur by Minimally Invasive Dynamic Hip Screw
}

\author{
Dayanand M, Deepak S, Manoj Kumar, Vijay Kumar, Mithun S Patil , \\ Bangalore Medical College and Research Institute, India
}

\begin{abstract}
Introduction: Intertrochanteric fractures comprise approximately $50 \%$ of all hip fractures. In view of associated comorbid conditions in elderly patients the aim of treatment is to prevent malunion and early mobilization, which is provided by Dynamic Hip Screw and Sliding Plate. A large exposure is necessary for implantation of the traditional 4 holed plate which leads to more blood loss and increased operating time adding to increased morbidity and mortality. The two holed side plate affords the surgeon the opportunity to implement a minimally invasive approach in certain intertrochanteric fractures like Boyd and Griffin type I and II fractures. This can potentially reduce operative time, blood loss and possibly improve patient outcome.

Materials and Method: A prospective study was done in 50 patients with Intertrochanteric fractures who were managed with dynamic hip screw and side plate using minimally invasive technique from November 2006 to December 2012 in our institute. Patients with type I and II Boyd and Griffin intertrochanteric fractures were included. Duration of surgery and Intraoperative blood loss was measured. All the patients were examined clinically and radiographically every 6 weeks and any complications were recorded. Sanders 60 point traumatic hip rating score was used to evaluate the functional results.

Results: The average follow up duration was 7 months ranging 3 to 18 months. One death occurred and one was lost to follow up. The average age of the patient was 60 years with a range of 21 to 80 years. There were 15 type I fractures and 35 type II fractures, The average surgical time was 45 minutes ranging from 30 to 80 min and average blood loss was $90 \mathrm{cc}$, The average time to union was 9 weeks ranging from 6 to 12 weeks. There were no nonunion. There was knee pain in 4 patients, shortening of less than or equal to $2 \mathrm{~cm}$ in 4 patients and one patient with superficial infection which responded to appropriate antibiotics. Two malunion with varus angulation of less than 10 degrees was seen. According to Sanders traumatic hip scoring there were $31 \%$ excellent results, $58 \%$ good results and $11 \%$ poor results. One death occurred due to comorbid conditions.

Conclusion: Minimally Invasive technique for the management of intertrochanteric fractures (types I and II Boyd and Griffin) with DHS and two holed side plate makes "biological osteosynthesis" possible with less operative time, minimal soft tissue stripping, minimal blood loss and adequate biomechanical stability. We conclude that minimally invasive DHS with 2 holed side plate is a reliable and reproducible technique, which requires initial learning curve.

Keywords: Dynamic Hip Screw, Minimally invasive surgery.
\end{abstract}

\section{Introduction}

Intertrochanteric fractures comprise approximately 50\% of all hip fractures .The incidence is more in female population compared to males due to osteoporosis. In spite of advances in anaesthesia, nursing care and surgical techniques, hip fractures remain a significant cause of morbity and mortality in the elderly population (2). In view of associated comorbid conditions in elderly patients the aim of treatment is to prevent malunion and early mobilization, which is provided by Dynamic Hip Screw and Sliding Plate. To date it has been used in a primarily open fashion with a relatively large exposure .A large exposure is necessary for implantation of the traditional 4 holed plate which leads to more blood loss and increased operating time adding to increased morbidity and mortality. However recent biomechanical data demonstrates equivalent peak load to failure results when comparing the two and four holed plate (3),(4). The two holed side plate affords the surgeon the opportunity to implement a minimally invasive approach in certain intertrochanteric fractures like Boyd and Griffin type I and II fractures .Insertion of short side plate reduces the size of necessary incision and degree of soft tissue disruption. This can potentially reduce operative time, blood loss and possibly improve patient outcome. Clinical and biomechanical data indicates that a two holed side plate could be sufficient for the treatment of stable intertrochanteric fractures that lack subtrochanteric extension.

In view of these considerations, this study was done to analyze the surgical management of intertrochanteric fractures using dynamic hip screw with two holed side plate using a minimally invasive technique and its outcome regarding pain relief, early mobilization and fracture union(1),(5),(6). 


\section{Materials and Method}

A prospective study was done in 50 patients with Intertrochanteric fractures who were managed with dynamic hip screw and side plate using minimally invasive technique from November 2006 to December 2012 in our institute. Patients with type I and II Boyd and Griffin intertrochanteric fractures were included. Subtrochanteric fractures, Pathological fractures, late presentations, Fractures with reverse obliquity, Poly trauma patients and Compound fractures were excluded. The patient was then taken up for surgery after investigations and as soon as the patient was medically fit for surgery for patients with medical co-morbidities. 2 holed DHS was implanted using an incision of 5-6cms under image intensifier after reduction in all the cases. Duration of surgery and Intraoperative blood loss was measured by weighing the mops and suction drain collection were recorded.

All the patients were examined clinically and radiographically every 6 weeks.

Radiographically evaluated for union, any varus or valgus angulation, collapse and any implant related complications. Sanders (32) traumatic hip rating score was used to evaluate the functional results. It emphasizes on pain, walking capacity, functional restriction, muscle and motion power, performance of daily activities and radiographic evaluation

\section{Results}

The average follow up duration was 7 months ranging 3 to 18 months. One death occurred and one was lost to follow up. The average age of the patient was 60 years with a range of 21 to 80 years. There were $64 \%$ males and $36 \%$ female patients. Majority of the fractures occurred due to road traffic accidents accounting for $75 \%$. were 15 type I fractures and 35 type II fractures, The average surgical time was 45 minutes ranging from 30 to $80 \mathrm{~min}$ and average blood loss was $90 \mathrm{cc}$, The average time to union was 9 weeks ranging from 6 to 12 weeks. There were no nonunion. We had our share of complications which included knee pain in 4 patients, shortening of less than or equal to $2 \mathrm{~cm}$ in 4 patients and one patient with superficial infection which responded to appropriate antibiotics. Two malunion with varus angulation of less than 10 degrees was seen. According to Sanders traumatic hip scoring there were $31 \%$ excellent results, 58\% good results and $11 \%$ poor results. One death occurred due to comorbid conditions.

\section{Discussion}

The dynamic hip screw with a side plate remains the most common method of treating the intertrochanteric hip fractures .Conventional surgical technique with appropriate dissection for hemostasis and fixation has stood the test of time for radiographic reduction and bone healing .Recently, the goals of treating these fractures have been to decrease the transfusion requirements, analgesic costs and operating room time in an attempt to mobilize the patient, reduce the convalescence period and hospital costs.(5) However, the use of custom or new implants, which are often more costly and require an increased hospital inventory of the devices, may be counter intuitive to this process(1),(3),(4).

Cephalomedullary nails have been designed to achieve these goals, however a meta-analysis of all the published trials shows that some of these devices had a significantly increased risk of fracture of the femoral shaft and an increased re-operative rate (5),(29). Reported blood loss and operative time varied in comparison to the standard DHS fixation ,but most randomized studies have reported little if no difference (In a study that prospectively examined 100 hip fractures repair, equally treated by a conventional dynamic hip screw and an intramedullary nail concluded with the following results : Intra-operative blood loss was $198 \mathrm{cc}$ and $144 \mathrm{cc}$ respectively and average operative time was $57 \mathrm{mins}$ and 78 mins respectively (29).

A percutaneously placed dynamic hip screw with side plate technique which has been evolved recently in view of achieving the above mentioned goals seems to have allowed reduced complications ,event free fracture healing and improved rehabilitation .In our study we used a 2 holed side plate and dynamic hip screw ,there is another device developed by Gotrified et al which can also be placed percutaneously ,but the disadvantage of this newer device is increased hospital inventory and re-introduction of the learning process for the surgeon which may off set the advantages of this system. ${ }^{31}$ Whereas the conventional DHS with an abbreviated side plate ( 2 holed) does not have those problems and at the same time fulfills the requirement of a percutaneously placed device which is clinically and biomechanically stable (3),(4).

McLoughlin et al studied the biomechanical strength and stiffness of a DHS with 2 holed side plate and a DHS with a 4 holed side plate .The results of their study revealed that the 2 holed side plate is biomechanically as stable as a 4 holed side plate in cyclic and failure loads under the conditions tested .They suggested that these results in concert with the clinical experience could be used to the support of using a 2 holed side plate in stable intertrochanteric fractures (types IandII Boyd and Griffin ) without subtrochanteric extension (4).

Mathew DiaPaola,BA et al in their study of minimal incision technique using a 2 holed side plate for fixation of stable intertrochanteric hip fractures reported an average incision size of $4-6 \mathrm{cms}($ avg $5 \mathrm{cms})$,blood loss of 
$41.9 \mathrm{cc}(20-50 \mathrm{cc})$ per surgery .Average operative time of $61 \mathrm{mins}$.Average time to union 13 weeks(7-24 weeks).(5)

In our series of 50 patients with intertrochanteric fractures, the average blood loss was $91 \mathrm{cc}$ (70$200 \mathrm{cc}$ ), average duration of surgery was $45 \mathrm{mins}(30-80 \mathrm{mins})$ and time to union was 9 weeks (6-12weeks). The functional outcome assessment using the Sanders traumatic hip scoring system(31) revealed that overall, there were $31 \%$ excellent, $58 \%$ good and $11 \%$ poor results. There were no implant failures or nonunion. None of the patients were bone grafted. As per the age of the patient, in those less than 50 years, there were $91 \%$ excellent to good results and the same was $87 \%$ in those more than 50 years. Our assessment depending on the type of fracture revealed that all the type I had good to excellent results and type II fractures had $83 \%$ excellent to good results. We had 4 patients with knee joint pain treated successfully with physiotherapy and analgesics, 4 patients with shortening of $2 /<2 \mathrm{cms}$ treated with shoe raise and 1 patient with superficial infection treated with adequate antibiotics and dressing. Our results were comparable with those of the others and also, this indicates that such a technique of using an abbreviated side plate which gives same biomechanical stability as a conventional one ,can be used in future for the treatment of stable (without subtrochanteric extension)intertrochanteric fractures. Advantages being that of reduced blood loss, union rates, early mobility and reduced use of analgesics .Though the technique is no more time intensive than the traditional approach and also has a learning curve as the surgeon has to adapt himself to closed reduction techniques ,it is certainly beneficial to the patients .Any surgery that requires transfusion, extended convalescence in a patient population similar to the hip fracture population presents a serious hit to the patient. So the minimally invasive technique in the management of these intertrochanteric fractures has its own advantages over the conventional and intramedullary devices.

\section{Conclusion}

Minimally Invasive technique for the management of intertrochanteric fractures (types I and II Boyd and Griffin) with DHS and two holed side plate makes "biological osteosynthesis" possible with less operative time, minimal soft tissue stripping, minimal blood loss and adequate biomechanical stability .It is a sound technique in treatment of these fractures in the age group it presents, as shown by good functional results and bone healing rates with reduced complications. We conclude that minimally invasive DHS with 2 holed side plate is a reliable and reproducible technique, which requires initial learning curve.

\section{References}

[1]. Alobaid A, Harvey EJ, Elder GM, Lander P, Guy P, Reindl R; Minimally invasive DHS: Prospective randomized trial of two techniques of insertion of a standard dynamic fixation device. J Ortho Trauma 2004;18(4)207-212.

[2]. Koval KJ, Zuckerman JD; Hip Fractures :A practical guide to management; Springer Intl: 138-140.

[3]. Bolhofner BR, Russo PR, Carmen, Barbara: Results of intertrochanteric femur fractures treated with a 135 degrees sliding screw with a two holed side plate ; J Orthop Trauma , $1999: 13(1) 5-8$.

[4]. McLoughlin SW, Wheeler DN, Rider J, Bolhofner BR; Biomechanical Evaluation of the Dynamic hip screw with two and four holed side plate ; J Orthop Trauma Vol 14(5);2000:318-323.

[5]. Mathew DiPaolo BA, S Robert Rozbruch, Helfet DC: Minimal incision technique using a two plate for fixation of stable intertrochanteric hip fractures; J Orthopaedics 2004: 126-132.

[6]. Farouk, Osama; Krettek, Christian; Miclav, Theodore;Schandelmaier, Peter;Guy,Pierre;Tscherne, Herald: Minimally invasive plate osteosynthesis : Does percutaneous plating disrupt femoral blood supply less than the traditional technique!; Orthop Trauma 2001:13(6) 394-400.

[7]. Smith Peterson MN, Cave EF, Van Gorder GW: Intracapsular fracture neck of femur .Arch Surg 1931; 23:715-759.

[8]. Jewett EL: One piece angle nail for trochanteric fractures; J Bone and Joint Surgery(B) 1941;23: 803-810.

[9]. Evans EM: The treatment of intertrochanteric fractures of Femur: J Bone and Joint Surgery (B) 1949; 31:190-203.

[10]. Boyd HB, Griffin LL: Classification and treatment of trochanteric fractures; Arch Surg 1949; 58: 853-866.

[11]. Schumpelick W, Jantzen PM: A new principle in the operative treatment of trochanteric fractures of the femur: J Bone and Joint Surgery (A) 1955; 37: 693-698.

[12]. Dimon JH, Hughston JC: Unstable intertrochanteric fractures of the hip; J Bone and Joint Surgery (A) 1967; 40: 440-450.

[13]. Harrington KD, Johnston JO: The management of comminuted unstable intertrochanteric fractures; J Bone and Joint Surgery (A) 1973; 55: 1367-1376.

[14]. Sarmiento A: Valgus osteotomy technique for unstable intertrochanteric fractures; The Hip: Proceedings of the third open scientific meeting of the hip society.St Louis: Mosby; 1975:157-169.

[15]. Ecker ML, Joyce JJ, and Kohl EJ: The treatment of trochanteric hip fracture using a compression screw: J Bone and Joint Surgery (A) $1975 ; 57: 23-27$.

[16]. Ganz R, Thomas RJ, Hammeerle CP: Trochanteric fractures of the femur: Treatment and Results. Clin Orthop 1979; 138: 30-40.

[17]. Martin RL, Zimmerman AA: Clinical study on internal fixation of femoral neck fractures .Clin Orthop 1979: 191-199.

[18]. Jacobs RR, McLain O, Armstrong HJ: Internal fixation of intertrochanteric fractures: A clinical and biomechanical study .Clin Orthop 1980;146:62-70.

[19]. Wolfgang CL, Bryant MH, O'Niel JP: Treatment of intertrochanteric fractures of femur using sliding screw plate fixation. Clin Orthop 1982; 163: 148-158.

[20]. Chacko V, Mohanty SP: Comparative analysis of operative and non operative management of trochanteric fractures. Indian J Orthop 1984;18: 19-22.

[21]. Kulkarni GS.: Treatment of trochanteric fractures of the hip by modified Richard's compressing and collapsing screw .Indian $\mathbf{J}$ Orthop 1984;18(!): 30-34. 
[22]. Gutler RA, Jacobs RR: Biomechanical evaluation of the ender's pin and the dynamic hip screw for unstable intertrochanteric fractures. Clin Orthop1986; 20:109-114.

[23]. Simpson AH,Varty K, Dodd CA.:Sliding hip screws modes of failure . Injury 1989;20: 227-231.

[24]. Klye RF, Cabanela ME, Russel TA,Zuckerman JD, Schmidt AH, Koval KJ:Fractures of the proximal part of the femur . Instr course Lect 1995;44: 227-253.

[25]. Baumgartner MR, Curtin SL, Lindskog DM , Keggi JM.: The value of tip apex distance in predicting failure of fixation of pertrochanteric fractures of the hip. J Bone and Joint Surgery (A) 1991;73:1192-1199.

[26]. O'Brien PJ, Meck RN, Blachut PA, Sabharwal S .Sliding screw plate fixation of the intertrochanteric femoral fractures. J Trauma 1972;12:581-591.

[27]. Butt MS, Krikler SJ, Nafie s, Ali MS:Comparison of dynamic hip screw and Gamma nail:A prospective ,randomized controlled trial. Injury 1995;26:615-618.

[28]. Parker MJ, Pyor GA: Gamma versus DHS nailing for extra capsular femoral fractures.Meta analysis of ten randomized trials .Internat Orthop 1996;20:163-168.

[29]. Hardy Dominique CR, Descamps FY, Kraths P: Use of an intramedullary hip screw compared with a compression with a plate for intertrochanteric femoral fractures. A prospective randomized study of 100 patients. J Bone and Joint Surgery (A) 1998; 80:

[30]. $618-630$.

[31]. Koval KJ, Friand KD, Aharanoff GB, Zuckerman JD: Post-operative weight bearing after a fracture of femoral neck or an intertrochanteric fracture. J Bone And Joint surgery(A) 1998; 80: 352-364.

[32]. Gotrified Y.:Percutaneous compression plating for intertrochanteric hip fractures.J Orthop Trauma 2000;14(7) : 490-495.

[33]. Sanders R, Regazzoni P : Treatment of subtrochanteric femur fractures using the dynamic condylar screw.J Orthop Trauma. 1989;3(3):206-13

\section{FIGURES:}

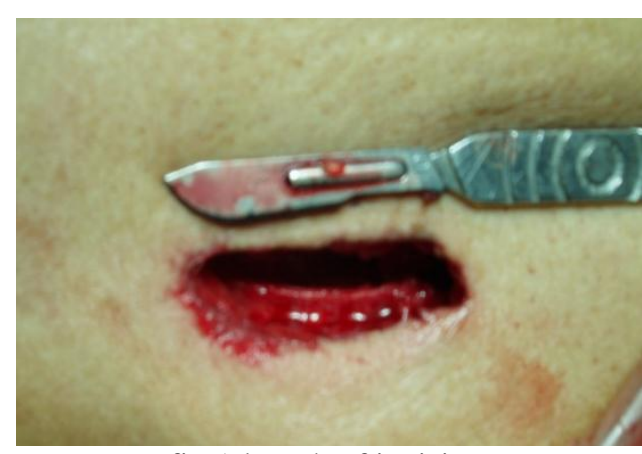

fig 1:length of incision



fig 2: guidewire insertion

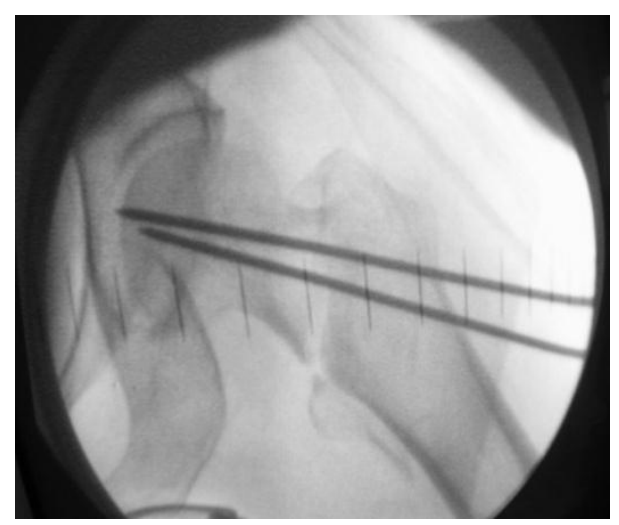

fig 3: $\mathrm{C}$ arm view 




fig 4: DHS in latral view



Fig 5: final seating of plate

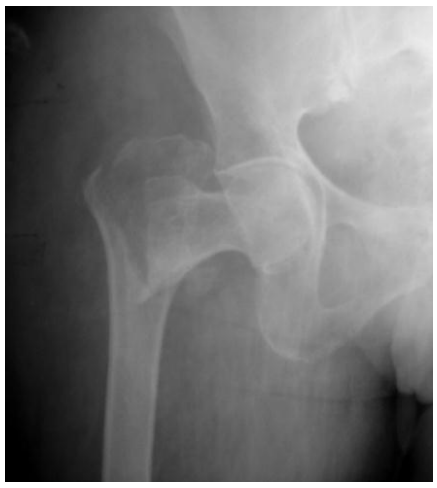

fig 6: pre op xray

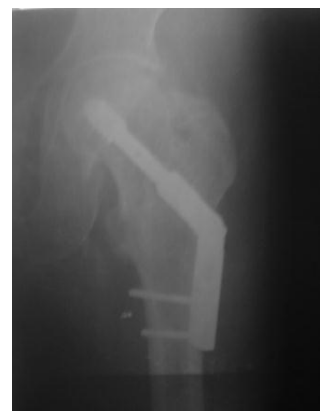

fig 7: immediate post op x ray

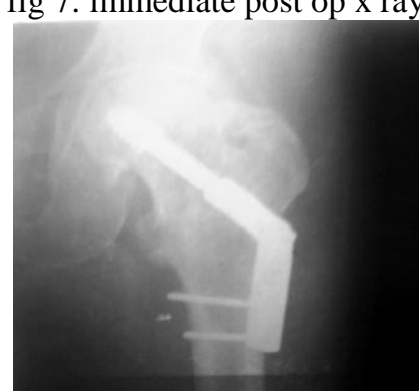

Fig 8: follow up 